\title{
Highly soluble cellulose nitrates from unconventional feedstocks
}

\author{
Yulia Gismatulina, Anna Korchagina, Vera Budaeva*, and Gennady Sakovich \\ ${ }^{1}$ Institute for Problems of Chemical and Energetic Technologies, Siberian Branch of the Russian Academy of Sciences, \\ 659322, 1 Socialisticheskaya Street, Biysk, Russian Federation
}

\begin{abstract}
Celluloses isolated by the nitric-acid process from domestic unconventional feedstocks such as Miscanthus, oat hulls, and intermediate flax straw were used herein to produce cellulose nitrates (CNs) with a high solubility. For the synthesis of $\mathrm{CNs}$, a commercial technique was employed that involves nitration of cellulose with mixed acid containing $14 \mathrm{wt}$.\% water followed by high-temperature treatment of the nitration product in acidic, alkaline, and neutral environments. The obtained CNs are similar in physicochemical attributes: $12.04-12.26 \%$ mass fraction of nitrogen, $10-14 \mathrm{mPa} \cdot \mathrm{s}$ viscosity, and $98 \%$ solubility in alcoholester mixture. FTIR spectra of CNs had absorption bands (2559-2557, 1646-1631, 1277-1271, 825-812, $747-744,683-680 \mathrm{~cm}^{-1}$ ) typical of nitro group vibrations. ${ }^{13} \mathrm{C}$ NMR spectra showed chemical shifts representative of 6-mononitrocellulose, 2,6-dinitrocellulose, 3,6-dinitrocellulose, and 2,3,6-trinitrocellulose. DSC revealed that the resultant CNs were highly chemically pure with an exothermic peak at $209-212^{\circ} \mathrm{C}$. The CNs obtained from the said unconventional feedstocks were compared with a commercial, highviscosity, lacquer-grade Colloxylin derived from cotton cellulose, as well as with other commercial Colloxylins, to show that the experimental CNs meet the requirements for comercial grades. Thus, the CNs obtained from the unconventional feedstocks are promising candidates as the component of composite explosives.
\end{abstract}

\section{Introduction}

Due to unique properties cellulose nitrates (CNs) are among the first and most important cellulose derivatives widely used in the manufacturing articles for defence and civil industrial sectors. Although NCs were discovered as early as the $18^{\text {th }}$ century, they are still of interest. Nowadays, CNs are utilized not only to fabricate conventional products (gun powder, explosives, paints and lacquers), but also to make new rocket propellant types [1]. Wu et al. [2] reported results on improving the plasticizing ability of $\mathrm{CN}$ by incorporating promising energetic binders (GAP) into the formulation. The thermal decomposition kinetics of $\mathrm{CN}$ mixed with high-energy oxidizers was studied $[3,4]$.

Young et al. [5] demonstrated the possibility of using nanosized aluminum mesoparticles with $\mathrm{CN}$ in rocket propellant formulations.

Along with that, $\mathrm{CNs}$ are finding new fields of application: for instance, they are used to prepare new filter membranes $[6,7]$ and a durable, room-temperature, curable, superhydrophobic, composite coating based on nitrocellulose lacquer [8]. Besides, different modifications of $\mathrm{CN}$ are tried to reduce its sensitivity to mechanical stimulus when used as a binder in insensitive high-energy propellants [9].

Corresponding author: budaeva@ipcet.ru
In Russia, research focused on expanding the assortment of civil Colloxylins by exploiting new cellulosic feedstocks is of special relevance [10].

CNs are typically produced from expensive cotton cellulose and scarce wood cellulose [11-13]. However, in recent years, the quality of products and stability of properties of cotton cellulose imported to Russia from near abroad countries (Uzbekistan and Kazakhstan) have deteriorated and the production of wood cellulose has been suspended because of environmental harm, difficult processing, and scarce forest resources.

To provide the nation with raw materials, preserve forests, and substitute imported high-cost cotton, an industrial base involving indigenous unconventional feedstocks needs to be developed. Fast-growing plants such as linen flax, hemp, melilot, hogweed, alfalfa, rape, and jute are especially attractive to scientists.

Overseas scholars consider esparto grass [14] and wood processing residues [15] as the potential source of cellulose and its nitrates. Not only plant cellulose but also bacterial cellulose as the promising source of $\mathrm{CNs}$ arouses interest of researchers. However, studies describing the synthesis of nitrates from those celluloses [16-18] give very little information on properties of CNs, making it difficult to assess their further application in practice.

Different advanced instruments are currently in use to evaluate the quality of CNs: scanning electron 
microscopy (Philips XL30, Quanta $600 \mathrm{~W}$ ), differential scanning calorimetry (DSC) and thermogravimetric analysis (TGA) (Stranton Redcroft STA-780), Fourier transform infrared spectroscopy (FTIR) (Nexus 670 FTIR, Shimadzu 8400S), difractometry (multipurpose difractometer with $\mathrm{Cu}-\mathrm{K} \alpha$ radiation), gas liquid chromatography (Agilent liquid chromatography series $1100)$, etc. $[19,20]$, as well as ${ }^{13} \mathrm{C}$ NMR spectroscopy [13].

At present, industrially important sources of feedstock with a high productivity are easily renewable crops and agricultural residues. Miscanthus is a fastgrowing peranneal crop with a high biomass yield of 1015 ton/ha/year over a span of 15-25 years. Oat hulls and intermediate flax straw are large-tonnage agricultural residues whose disposal issue has not yet been resolved.

However, replacing elite cotton feedstocks by unconventional raw materials to produce high-quality $\mathrm{CNs}$ is still at a lab scale, and there is no information at all about the feasibility of utilizing Miscanthus-, oat hulland intermediate flax straw-derived $\mathrm{CNs}$ as the component of composite explosives, making this research area undoubtedly topical.

The present study aimed to synthesize CNs from Miscanthus, oat hulls, and intermediate flax straw to explore whether the CNs could be used as the constituent of composite explosives.

\section{Experimental part}

The substrates for this study were celluloses isolated from Miscanthus (M), oat hulls $(\mathrm{OH})$, and intermediate flax straw (IFS) by the nitric-acid method [21, 22] at the pilot production site of IPCET SB RAS.

The feedstocks prior to pulping were ground on a garden chaff cutter to at most $10 \mathrm{~mm}$. The nitric-acid process for cellulose involved the following stages: step by step treatment at $94 \pm 2{ }^{\circ} \mathrm{C}$ with $0.4 \% \mathrm{HNO}_{3}, 5 \%$ $\mathrm{HNO}_{3}, 2 \% \mathrm{NaOH}$, and $0.8 \% \mathrm{NaOH}$ prior to eventual decationation (souring) by treatment with $0.8 \% \mathrm{HNO}_{3}$ at $50^{\circ} \mathrm{C}$ to furnish the target cellulose.

Mass fractions of $\alpha$-cellulose, ash, acid-insoluble lignin, pentosans were measured by standard procedures [23]. The cellulose degree of polymerization (DP) was determined from the viscosity of solutions in cadoxene on a VPZh-3 viscometer (ECROS, Russia) with a capillary of $0.92 \mathrm{~mm}$ in diameter [24].

A commercial nitration method was used to produce CNs from Miscanthus, oat hulls and intermediate flax straw. This method involved the treatment of celluloses with mixed acid containing $14 \mathrm{wt} . \%$ water in a solid-toliquid ratio of $1: 25(\mathrm{w} / \mathrm{v})$ at $33 \pm 2^{\circ} \mathrm{C}$ for $35 \mathrm{~min}$. After the nitration was completed, the resultant $\mathrm{CNs}$ were washed with water until neutral reaction and treated in acidic, alkaline, and neutral medium under the following conditions: $1 \mathrm{~h}$ boiling in water at $85 \pm 2^{\circ} \mathrm{C} ; 1.5 \mathrm{~h}$ autoclaving in $0.3 \% \mathrm{HNO}_{3}$ at $130 \pm 2^{\circ} \mathrm{C} ; 3 \mathrm{~h}$ boiling in $0.03 \% \mathrm{Na}_{2} \mathrm{CO}_{3}$ at $85 \pm 2{ }^{\circ} \mathrm{C}$ followed by $1 \mathrm{~h}$ exposure to water at $85 \pm 5^{\circ} \mathrm{C}[21,22]$.

The $\mathrm{CN}$ samples were dried at room temperature and then at $100 \pm 2^{\circ} \mathrm{C}$ for $1 \mathrm{~h}$ until a moisture not above $5 \%$, and were further characterized.
The commercial, high-viscosity, lacquer-grade Colloxylin made of cotton cellulose was used as the control.

The mass fraction of nitrogen was quantified by the ferrous sulfate method, which consisted in saponifying $\mathrm{CNs}$ with concentrated sulfuric acid and reducing the formed nitric acid with iron (II) sulfate to nitrogen oxide that generates, in excess of iron (II) sulfate, a $[\mathrm{Fe}(\mathrm{NO})] \mathrm{SO}_{4}$ complex compound that turns the solution yellow-pink. This method is still in demand in the world practice [13].

The CN viscosity was determined by measuring the flow time of the $2 \% \mathrm{CN}$-acetone solution out of a VPZh1 viscosimeter with a capillary diameter of $2.10 \mathrm{~mm}$. The CN solubility in acetone was $100 \%$.

The solubility of CNs in an alcohol-ester mixture was measured by filtration of the $\mathrm{CN}$ residue insoluble in the alcohol-ester mixture with subsequent drying and weighing. The $\mathrm{CN}$ solutions in the alcohol-ester mixture were poured into crystallizers, evaporated in a fume hood until thin films were formed, and the film transparency was evaluated macroscopically.

The information on the molecular structure of CNs was acquired by FTIR spectroscopy. IR spectra were recorded on an Infralum-801 spectrometer (NPF Simex, Russia) in the frequency range of $4000-500 \mathrm{~cm}^{-1}$. To take spectra, pellets were pressed in potassium bromide in an $\mathrm{CN} / \mathrm{KBr}$ ratio of $1: 150$.

The $\mathrm{CN}$ samples were characterized by ${ }^{13} \mathrm{C}$ NMR spectroscopy on a Bruker Avance $400 \mathrm{MHz}$ NMR spectrometer (Bruker, Germany) at $60^{\circ} \mathrm{C}$ with an operating frequency of $100.61 \mathrm{MHz}$, with DMSO- $d_{6}$ solvent.

Additionally, CNs were analyzed by DSC on a DTG60 thermogravimetric analyzer (Shimadzu, Japan): 0.5 $\mathrm{mg}$ sample weight, $10^{\circ} \mathrm{C} / \mathrm{min}$ heating rate, $350^{\circ} \mathrm{C}$ maximum temperature, and nitrogen as inert medium.

All the reagents were manufactured in Russia: nitric acid (AO Azot), sulfuric acid (SigmaTec), sodium hydroxide (AO Kaustik), acetone (GC Titan), diethyl ether (Kuzbassorghim), ammonium ferrous sulphate (Khimreaktiv), ethylenediamine (Chemiline), mixed acid (Biysk Oleum Factory).

The analyses were done with instruments of the Biysk Regional Center for Shared Use of Scientific Equipment of the SB RAS (IPCET SB RAS, Biysk).

\section{Results and discussion}

In the manufacture of products for defense and civil industries, the highest quality $\mathrm{CNs}$ are produced from linter or wood cellulose having an $\alpha$-cellulose content of $92-98 \%$ and the lowest overall content of noncellulosics. The chemical composition of cellulose samples obtained from Miscanthus, oat hulls, and intermediate flax straw by the nitric-acid process at the pilot production site of the IPCET SB RAS are summerized in Table 1.

Cellulose samples isolated from the unconventional feedstocks by the nitric-acid process exhibit a high $\alpha$ cellulose content of 88-94\% and a high degree of polymerization at $820-1420$ (Table 1). The overall 
content of non-cellulosic constituents of the Miscanthus, oat hull and intermediate flax straw celluloses is $3.43 \%$, $3.03 \%$ and $5.0 \%$, respectively, which makes the preparation of CNs highly soluble in the alcohol-ester mixture, problematic.

Table 1. Chemical composition of cellulose samples obtained from Miscanthus, oat hulls, and intermediate flax straw by the nitric-acid process at the pilot production site of IPCET SB RAS.

\begin{tabular}{|c|c|c|c|c|c|}
\hline \multirow[b]{2}{*}{$\begin{array}{c}\text { Cellulose } \\
\text { sample }\end{array}$} & \multicolumn{4}{|c|}{ Content, \% } & \multirow[b]{2}{*}{ DP } \\
\hline & 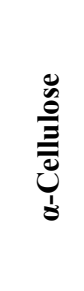 & 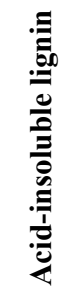 & 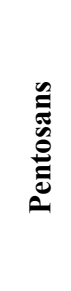 & $\frac{\bar{n}}{4}$ & \\
\hline Miscanthus & 90.70 & 1.81 & 0.67 & 0.95 & 940 \\
\hline Oat hulls & 94.29 & 0.32 & 2.30 & 0.41 & 1420 \\
\hline $\begin{array}{l}\text { Intermediate } \\
\text { flax straw }\end{array}$ & 87.83 & 2.41 & 1.10 & 1.49 & 820 \\
\hline
\end{tabular}

The comparison between the celluloses showed that the oat hull cellulose had the best quality (94 \% $\alpha$ cellulose and 1420 DP) togetehr with a high natural homogeneity, and therefore the oat hull cellulose is preferred for preparing $\mathrm{CN}$ and making composite explosives.

Physicochemical characteristics of the obtained CNs and commercial, high-viscosity, lacquer-grade, cotton Colloxylin (CC) are listed in Table 2.

Table 2. Physicochemical characteristics of Miscanthus, oat hull and intermediate flax straw CNs and of cotton Colloxylin.

\begin{tabular}{|c|c|c|c|}
\hline \multirow{2}{*}{$\begin{array}{c}\text { CN } \\
\text { sample }\end{array}$} & \begin{tabular}{c}
$|c|$ \\
Characteristics \\
\cline { 2 - 4 } \\
fraction \\
of \\
nitrogen, \\
\%
\end{tabular} & $\begin{array}{c}\mathbf{2 \%} \text { CN- } \\
\text { acetone } \\
\text { solution } \\
\text { viscosity, } \\
\text { mPa·s }\end{array}$ & $\begin{array}{c}\text { Solubility in } \\
\text { alcohol-ester } \\
\text { mixture, \% }\end{array}$ \\
\hline M & 12.26 & 14 & 98 \\
\hline OH & 12.12 & 10 & 98 \\
\hline IFS & 12.04 & 12 & 98 \\
\hline $\mathrm{CC}$ & 12.34 & 15 & 98 \\
\hline
\end{tabular}

It is seen from data in Table 2 that the $\mathrm{CN}$ samples from Miscanthus, oat hulls and intermediate flax straw have nearly the same parameters: $12.04-12.26 \%$ mass fraction of nitrogen, $10-14 \mathrm{mPa} \cdot \mathrm{s}$ viscosity, and $98 \%$ solubility in alcohol-ester mixture. The comparison between the $\mathrm{CN}$ samples shows that they are comparable.
The high solubility values of the experimental CNs (98\%) and the transparency of the $\mathrm{CN}$ films dried after analysis suggest that no nitrated hemicellulose residues are present in the CNs. The CNs obtained from the unconventional feedstocks are commensurable in properties listed in Table 2 with the commercial, highviscosity, lacquer-grade, cotton Colloxylin and with other commercial Colloxylins, which indicates their further potential for use in composite explosives.

The assignment of bands in the IR spectra of the Miscanthus, oat hull and intermediate flax straw CNs and of the commercial, high-viscosity, lacquer-grade, cotton Colloxylin is set out in Table 3.

Table 3. Band assignment in IR spectra of Miscanthus, oat hull and intermediate flax straw $\mathrm{CNs}$ and of cotton Colloxylin.

\begin{tabular}{|c|c|c|c|c|}
\hline \multirow{3}{*}{ Assignment } & \multicolumn{4}{|c|}{$\mathbf{C N}$} \\
\hline & $\mathbf{M}$ & OH & IFS & $\mathrm{CC}$ \\
\hline & \multicolumn{4}{|c|}{ Frequency, $\mathrm{cm}^{-1}$} \\
\hline $\begin{array}{l}v(\mathrm{OH})(\mathrm{OH} \ldots \mathrm{OH}) \\
\text { stretching }\end{array}$ & 3569 & 3568 & 3564 & 3439 \\
\hline$v\left(\mathrm{CH}_{2}\right)$ stretching & 2925 & 2922 & 2921 & 2922 \\
\hline $2 v\left(\mathrm{NO}_{2}\right)$ stretchning & 2559 & 2558 & 2559 & 2557 \\
\hline$v_{\mathrm{a}}\left(\mathrm{NO}_{2}\right)$ stretching & 1659 & 1660 & 1666 & 1660 \\
\hline$\sigma\left(\mathrm{CH}_{2}\right)$ bending & 1631 & 1639 & 1632 & 1646 \\
\hline$\sigma(\mathrm{COH})$ bending & 1435 & 1428 & 1444 & 1430 \\
\hline$\sigma(\mathrm{CH})$ bending & 1379 & 1379 & 1379 & 1381 \\
\hline $\begin{array}{l}v_{\mathrm{s}}\left(\mathrm{NO}_{2}\right) \text { symmetric } \\
\text { valence }\end{array}$ & 1275 & 1277 & 1275 & 1271 \\
\hline$v(\mathrm{C}-\mathrm{O})$ stretching & 1164 & 1164 & 1165 & 1167 \\
\hline$v(\mathrm{C}-\mathrm{O})$ stretching & 1071 & 1072 & 1074 & 1073 \\
\hline$\sigma(\mathrm{CH})$ bending & 1002 & 1000 & 1002 & 1001 \\
\hline$v\left(\mathrm{NO}_{2}\right)$ stretching & 822 & 825 & 823 & 812 \\
\hline$\gamma \mathrm{w}\left(\mathrm{NO}_{2}\right)$ wagging & 744 & 747 & 745 & 746 \\
\hline$\delta\left(\mathrm{NO}_{2}\right)$ sissoring & 683 & 681 & 680 & 680 \\
\hline
\end{tabular}

All the IR spectra of the synthesized CNs show intrinsic frequencies indicating the structural features of $\mathrm{CN}$ macromolecules.

It follows from data in Table 3 that the IR spectra of the CNs have $v(\mathrm{OH})$ stretching peaks as a broad band with complex contour around 3700-3200 $\mathrm{cm}^{-1}$, which suggests an incomplete substitution of $\mathrm{CN}$. Those peaks belong to $\mathrm{CN}$ hydroxyls involved in hydrogen bonding and are a fingerprint of the chemical inhomogeneity of $\mathrm{CN}$.

The absorption band around 2925-2921 $\mathrm{cm}^{-1}$ is responsible for $\mathrm{CH}$ stretching. Stretching vibrations of nitrate groups relate to the absorption band around 2559- 
$2557 \mathrm{~cm}^{-1}$. Several bands are overlapped in the IR spectra of the CNs around $1700-1500 \mathrm{~cm}^{-1}$.

The absorption band around 1666-1659 $\mathrm{cm}^{-1}$ was assigned to $v_{\mathrm{a}}\left(\mathrm{NO}_{2}\right)$ associated with $\mathrm{CH}$ groups of the glucopyranose rings of $\mathrm{CN}$ (position $\mathrm{C}_{(2)}$ and/or $\mathrm{C}_{(3)}$ ). The intense band around $1646-1631 \mathrm{~cm}^{-1}$ was attributed to $v_{\mathrm{a}}\left(\mathrm{NO}_{2}\right)$ associated with $\mathrm{CH}_{2}$ groups of glucopyranose rings of $\mathrm{CN}$ (position $\mathrm{C}_{(6)}$ ). This is in good agreement with assignment data of the $v_{\mathrm{a}}\left(\mathrm{NO}_{2}\right)$ band of primary and secondary alcohols. The substitution of $\mathrm{OH}$ group by $\mathrm{NO}_{2}$ group is known to occur mostly at the $\mathrm{C}_{(6)}$ position and inequally at positions $\mathrm{C}_{(2)}$ and $\mathrm{C}_{(3)}$, depending on the etherification degree.

The absorption band around 1444-1428 $\mathrm{cm}^{-1}$ was attributed to $\mathrm{CH}_{2}$ sissoring vibrations. The IR spectra of the CNs have absorption bands around 1381-1379 $\mathrm{cm}^{-1}$ and $1277-1271 \mathrm{~cm}^{-1}$, whose intensities markably decrease as the mass fraction of nitrogen declined. The band at 1381-1379 $\mathrm{cm}^{1}$ was assigned to bending vibrations of $\mathrm{CH}$ groups in $\mathrm{CH}_{2} \mathrm{ONO}_{2}$. The absorpton band at $1277-1271 \mathrm{~cm}^{-1}$ correspond to $\mathrm{NO}_{2}$ symmetric stretch. The absorption band at $1167-1164 \mathrm{~cm}^{-1}$ refers to stretching vibrations of glycosidic linkage. In the region of $1100-1000 \mathrm{~cm}^{-1}$, there is a band at $1074-1071 \mathrm{~cm}^{-1}$ relating to stretching of $\mathrm{C}-\mathrm{O}$ bonds linking the pyranose rings. In the IR spectra of the $\mathrm{CNs}$, there appear some bands due to the absorption of nitrate groups around $825-812,747-744$ and $683-680 \mathrm{~cm}^{-1}$ pertaining to N-O stretch, $\mathrm{NO}_{2}$ out-of-plane pendulum vibrations and $\mathrm{N}-\mathrm{O}$ in-plane bending, respectively [25].

The comparison between the IR spectra of the CNs obtained from the unconventional feedstocks and of the high-viscosity, lacquer-grade, cotton Colloxyline showed their likeness in terms of basic absorption bands corresponding to nitro group vibrations. The absorption bands of the Miscanthus, oat hull and intermediate flax straw CNs were also found to correspond to the reference data on commercial Colloxylins, validating CNs derived from the unconventional feedstocks.

${ }^{13} \mathrm{C}$ NMR spectra of the Miscanthus, oat hull and intermediate flax straw CNs and of the high-viscosity, lacquer-grade, cotton Colloxylin are given in Figure 1.

The ${ }^{13} \mathrm{C}$ NMR spectra of the synthesized CNs show chemical shifts representative of 6-mononitrocellulose at 102.1 ppm, 2,6-dinitrocellulose at $97.4 \mathrm{ppm}, 3,6-$ dinitrocellulose at 82.8, 82.9 and $83.0 \mathrm{ppm}$, and 2,3,6trinitrocellulose at 99.0, 99.2, 79.3 and 79.4 ppm [25].

The Miscanthus, oat hull and intermediate flax straw CNs were found to hold 6-mono-, 2,6-di- and 2,3,6trisubstituted moieties of the pyranose ring, and most chemical shifts of the Miscanthus, oat hull and intermediate flax straw CNs match those of the highviscosity, lacquer-grade, cotton Colloxylin, indicating that the chemical structure of the CNs obtained from the said unconventional feedstocks are identical to the cotton CN.

The TGA/DSC characteristics of the CNs obtained from Miscanthus, oat hulls and intermediate flax straw and of high-viscosity, lacquer-grade, cotton Colloxylin are given in Table 4.

DSC calorimetry revealed that all the CNs shared one narrow exothermic peak between $209^{\circ} \mathrm{C}$ and $212^{\circ} \mathrm{C}$ accompanied by the sample weight loss to $82-91 \%$. TGA curves of the CNs derived from the unconventional feedstocks coincide with those of the high-viscosity, lacquer-grade, cotton Colloxylin. The findings obtained herein suggest a high chemical purity of the synthesized CNs $[14,25]$. The present exothermic peak and heat of decomposition in the range of $6-7 \mathrm{~kJ} / \mathrm{g}$ in the inert medium indicate a highly energetic nature of the substance decomposition.
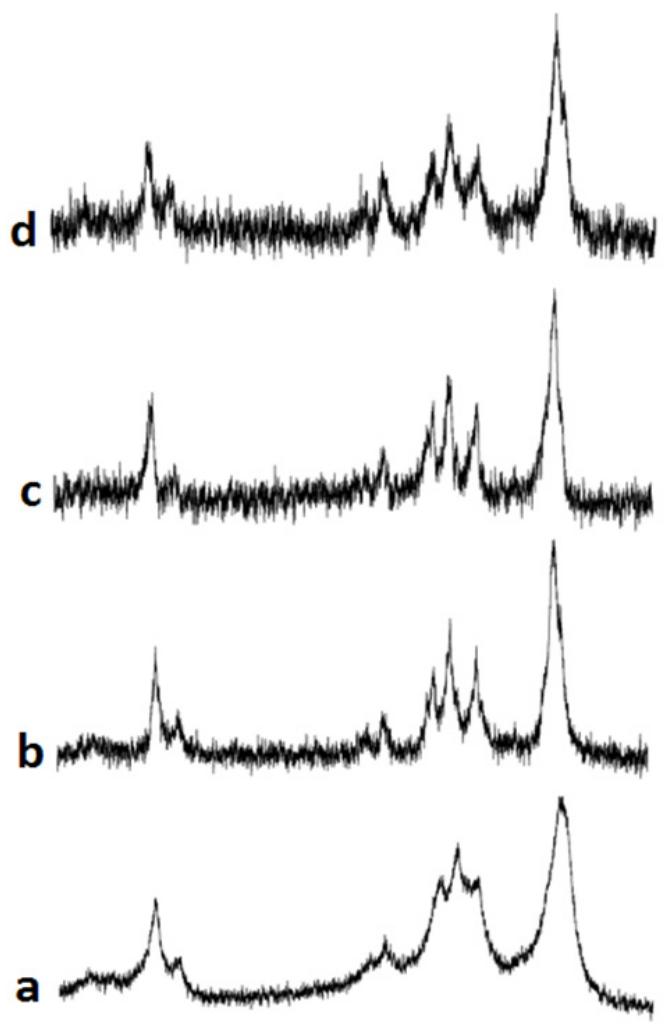

\begin{tabular}{llllllllll}
\hline 105 & 100 & 95 & 90 & 85 & 80 & 75 & .70 & 65 & $\mathrm{ppm}$
\end{tabular}

Fig. 1. ${ }^{13} \mathrm{C}$ NMR spectra of CNs obtained from (a) Miscanthus; (b) oat hulls; (c) intermediate flax straw and (d) high-viscosity, lacquer-grade, cotton Colloxylin.

Table 4. TGA/DSC characterization of CNs obtained from Miscanthus, oat hulls and intermediate flax straw and of cotton Colloxylin.

\begin{tabular}{|c|c|c|c|}
\hline \multirow{2}{*}{$\begin{array}{c}\text { CN } \\
\text { sample }\end{array}$} & \multicolumn{3}{|c|}{ Characteristics } \\
\cline { 2 - 4 } & $\begin{array}{c}\text { Weight } \\
\text { loss, \% }\end{array}$ & $\begin{array}{c}\text { Exothermic } \\
\text { peak, }{ }^{\circ} \mathbf{C}\end{array}$ & $\begin{array}{c}\text { Heat, } \\
\mathbf{k J} / \mathbf{g}\end{array}$ \\
\hline $\mathrm{M}$ & 85 & 212 & 6,66 \\
\hline $\mathrm{OH}$ & 91 & 211 & 7,54 \\
\hline $\mathrm{IFS}$ & 82 & 210 & 6,28 \\
\hline $\mathrm{CC}$ & 86 & 209 & 5,83 \\
\hline
\end{tabular}




\section{Conclusion}

Cellulose nitrates (CNs) have been synthesized from domestic unconventional feedstocks such as Miscanthus, oat hulls and intermediate flax straw by an industrial technique using mixed acid, and exhibit similar physicochemical properties: $12.04-12.26 \%$ mass fraction of nitrogen, $10-14 \mathrm{mPa} \cdot \mathrm{s}$ viscosity, and $98 \%$ solubility in alcohol-ester mixture. The IR spectra of the CNs derived from Miscanthus, oat hulls, and intermediate flax straw show basic absorption bands corresponding to nitro group vibrations: 2559-2557, 1646-1631, 1277$1271,825-812,747-744$, and $683-680 \mathrm{~cm}^{-1}$. The ${ }^{13} \mathrm{C}$ NMR spectra of the synthesized $\mathrm{CNs}$ have chemical shifts typical of 6-mononitrocellulose, 2,6dinitrocellulose, 3,6-dinitrocellulose, and 2,3,6trinitrocellulose. DSC reveals that the prepared CNs have a high-temperature exothermic peak $\left(209-212^{\circ} \mathrm{C}\right)$ with the weight loss to $82-91 \%$, indicating that the CNs are high quality.

The comparison between the unconventional feedstock-derived $\mathrm{CNs}$ and high-viscosity, lacquergrade, cotton Colloxylin shows that the experimental CNs match commercial Colloxylins in terms of basic properties and can therefore be advised as the component of composite explosives. Our suggestion to replace cotton nitrocellulose by CNs from alternative feedstocks is justified by their comparable basic properties but is not evident because the polymer inhomogeneity together with the considerable mass content of short fibers do not guarantee a high plasticizing ability of the experimental CNs. Nevertheless, the positive findings obtained in this study allow us to continue the started research.

The work was supported by Basic Research Program of the Russian Academy of Science, Presidium No.56 'Fundamental Principles of Breakthrough Technologies for National Security' (Project No. 0385-2018-0015).

\section{References}

1. M. Abd-Elghany, T.M. Klapötke, B. Krumm, A. Elbeih. Chem. Plus. Chem. 83, 128 (2018)

2. W. Yanguang, L. Yunjun, G. Zhen. PEP. 40, 67 (2015)

3. M. Abd-Elghany, T.M. Klapötke, A. Elbeih. PEP. 42, 1373 (2017)

4. M. Abd-Elghany, T.M. Klapötke, A. Elbeih. JAAP. 128, 397 (2017)

5. G. Young, H. Wang, M.R. Zachariah. PEP. 40, 413 (2015)
6. J.G. Fernández, C.A. Almeida, M.A. FernándezBaldo, E. Felici, J. Raba, M.I. Sanz. Talanta. 146, 237 (2016)

7. A.N. Olcay, M. Polat, H. Polat. Coll. Surf. A. 492, 199 (2016)

8. Y. Tian, K. Guo, X. Bian, T. Wang, S. Chen, J. Sun. Surf. Coat Tech. 328, 444 (2017)

9. X. Meng, Z. Xiao. PEP. 43, 1 (2018)

10. A.E. Golubev, S.A. Kuvshinova, V.A. Burmistrov, O.I. Koifman. RUGC. 88, 2, 368 (2018)

11. J.P Agrawal, R.D. Hodgson. Organic chemistry explosives (Wiley, England, 2007)

12. H.G. Ang, Sreekumar Pisharath. Energetic Polymers: Binders and Plasticizers for Enhancing Performance (Wiley-VCH Verlag GmbH \& Co.KGaA, Weinheim, 2012)

13. D. Budgell. Nitrocellulose: a cellulose raw material perspective. $7^{\text {th }}$ Nitrocellulose Symposium (Montreal, Canada, 2016)

14. D. Trache, K. Khimeche, A. Mezroua, M. Benziane. Therm. Anal. Calorim. 124 (3), 1485 (2016)

15. I.M. Adekunle. J. Chem. 7(3), 709 (2010)

16. H. Yamamoto, F. Horii, A. Hirai. Cellulose. 13, 327 (2006)

17. D. Sun, B. Ma, C. Zhu, C. Liu, J. Yang. J. Energ. Mater. 28, 85 (2010)

18. E. Colclough, R. Endsor, J. Hamid, S. Torry. Bacterial Cellulose - Analysis and Nitration. $7^{\text {th }}$ Nitrocellulose Symposium (Montreal, Canada, 2016)

19. M.R. Sovizi, S.S. Hajimirsadeghia, B. Naderizadeh. J. Hazard. Mater. 168, 1134 (2009)

20. M. Lypez-Lypez, M. Angeles Fernandez de la Ossa, J.S. Galindo, J.L. Ferrando, A. Vega, M. Torre, C. Garcia-Ruiz. Talanta. 81, 1742-1749 (2010)

21. Yu.A. Gismatulina, V.V. Budaeva, G.V. Sakovich. PEP 43, 96 (2018)

22. Yu.A. Gismatulina, V.V. Budaeva, G.V. Sakovich. Russ. Chem. Bull. 65, 12, 2920 (2016)

23. A.V. Obolenskaya, Z.P. Yelnitskaya, A.A. Leonovich, Laboratornye Raboty Po Khimii Drevesiny I Tsellyulozy (Laboratory Works on Wood and Cellulose Chemistry: Textbook for Higher Educational Institutions, Ecology Publisher, Moscow, 1991 (in Russian), available at http://www.twirpx.com/file/190572 24. K.V. Gensh, P.V. Kolosov, N.G. Bazarnova. Russ J. Bioorg. Chem. 37/7, 814 (2011)

25. V.I. Kovalenko, R.M. Mukhamadeeva, L.N. Maklakova. J. Struct. Chem. 34, 540 (1994) 